\title{
Avaliação Físico-Química da Qualidade da Água, Relação com uso do Solo na Bacia do Ribeirão Santo Antônio
}

\section{Sandro M. Pimenta, Claudia V. de Lima \& Tiago G. Ribeiro}

O processo de ocupação urbana no município de Aparecida de Goiânia contribuiu para geração de impactos nos recursos naturais e meio social. Na década de 80, loteamentos foram regularizados sem a implantação de infraestrutura. O córrego Santo Antonio é a principal drenagem do município, ocupando $54 \%$ da área total deste. Realizou-se a avaliação físico-química da qualidade das águas do córrego Santo Antonio, identificando os impactos e correlacionando-os com o uso do solo. A avaliação foi realizada pela determinação de 11 pontos de amostragem, e 15 parâmetros de qualidade. As análises físico-químicas foram feitas no Laboratório de Geoquímica da UnB.

Palavras-chave: Análise Físico-Química, Qualidade da Água, Uso do Solo.

The process of urban occupation in the city of Aparecida de Goiânia contributed to generation of impacts on natural and social environment. In the $80 \mathrm{~s}$, lots were settled without the deployment of infrastructure. river Santo Antonio is the main drainage of the city, occupying $54 \%$ of the total area. There was a physical-chemical assessment of water quality of the river Santo Antonio, identifying impacts and correlating them with the use of soil. The evaluation was performed by determination of 11 sampling points and 15 parameters of quality. The physicist-chemistries analyses have been made in the Laboratory of Geochemistry of the UnB.

Key words: Physical-Chemical Assessment, Water Quality, Soil Use. 


\section{Introdução}

A área avaliada refere-se à bacia hidrográfica do Córrego Santo Antônio, localizada no município de Aparecida de Goiânia/GO, região sul do aglomerado urbano de Goiânia. O município dista aproximadamente $11 \mathrm{~km}$ da capital Goiânia, possui área total aproximada de $292 \mathrm{~km}^{2}$, com altitude em torno de 808 metros, sendo a segunda maior cidade em população do estado de Goiás (Figura 1).

O crescimento populacional do município, segundo o censo do IBGE, no período de 1996 a 2004, foi de $51 \%$, conseqüentemente cresce a demanda por recursos naturais, intensificando os impactos ambientais gerados pelo uso e ocupação do ambiente urbano.

O município possui clima, segundo a classificação de Kooeppen (1948), tipo Aw, tropical úmido, caracterizado por duas estações bem definidas: uma seca (maio a agosto) e outra chuvosa (outubro a abril). A temperatura media anual é de $22^{\circ} \mathrm{C}$.

O córrego Santo Antônio é a principal drenagem do município de Aparecida de Goiânia, possui extensão aproximada de $28,33 \mathrm{~km}$ e atravessa o município desaguando no Rio Meia Ponte. Sua bacia representa cerca $54 \%$ da área total do município contendo praticamente toda a área urbana. Os principais tributários são os Córregos: Itapoá, Granada, Tamanduá, Barreiro, Almeida e da Lagoa.

A geologia da área da bacia é representada por rochas metamórficas do Grupo Araxá, inseridas no contexto morfológico do Planalto Central Goiano, mais especificamente, na subunidade Planalto Rebaixado de Goiânia ${ }^{1}$.

Foram identificados quatro grupos de solos principais, sendo eles: Latossolos Vermelhos, Cambissolos, Neossolos Litólicos e Gleissolos, todos distróficos. Há predominância dos Latossolos e dos Cambissolos, em menor proporção os Neossolos Litolicos e em pequenas ocorrências os Gleissolos ${ }^{2}$.

A obtenção de informações integradas sobre um corpo de água avaliado depende basicamente do estudo das interações que ocorrem entre os fatores do meio físico e antrópicos. Estas interações estão vinculadas a uma escala temporal, refletindo um comportamento dinâmico e imprevisível, intrínseco a cada ambiente.

A pesquisa visa uma avaliação físico-química quanto à qualidade das águas do córrego Santo Antônio, identificando os principais impactos ambientais e passivos, correlacionando-os com o uso e ocupação do solo na bacia.

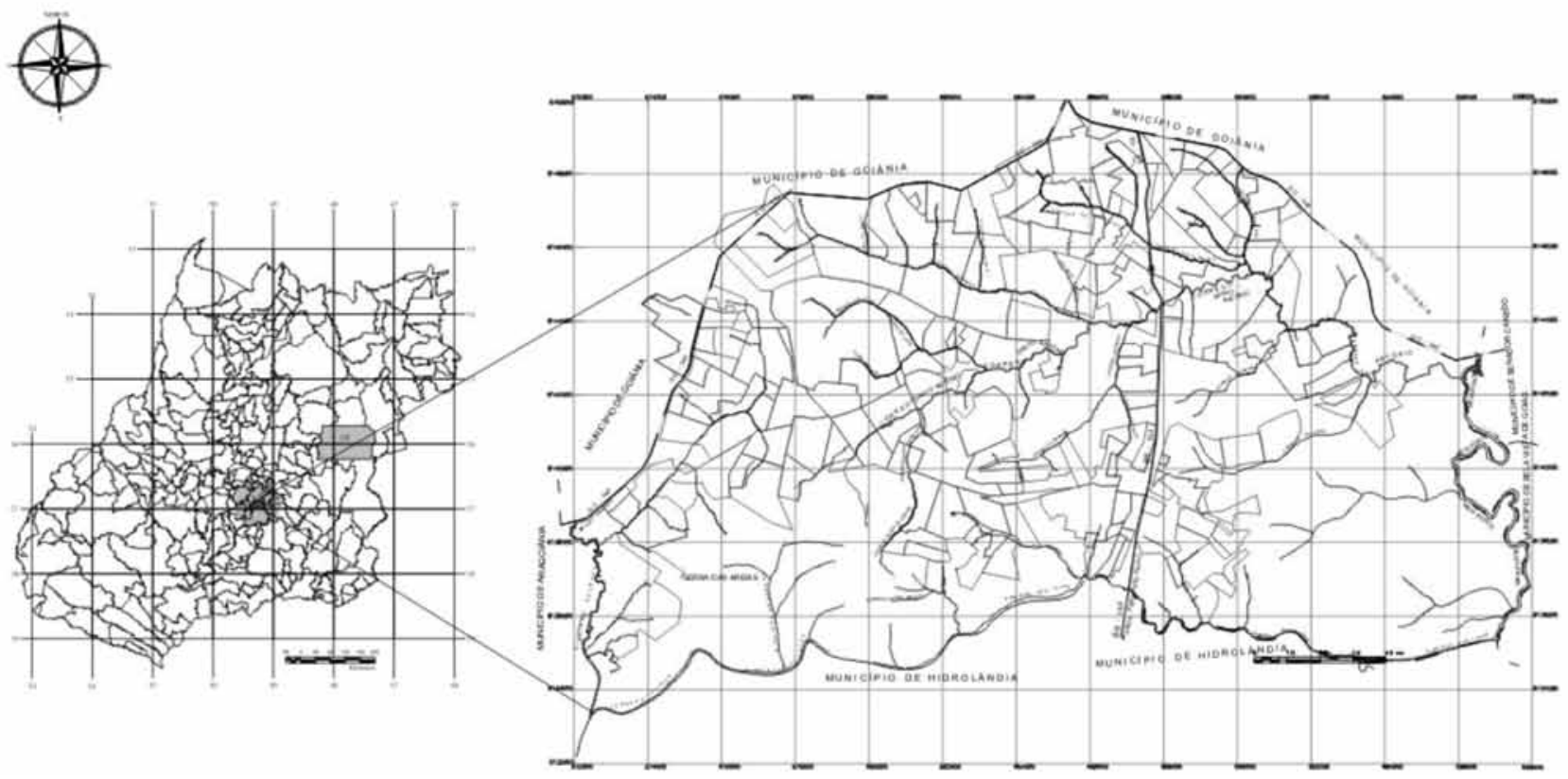

Figura 1: Localização do município de Aparecida de Goiânia. 


\section{Materiais e Métodos}

O desenvolvimento da pesquisa ocorreu em etapas sucessivas, buscando o entendimento do problema (conceitos, caracterização detalhada da área) e das metodologias de estudo, prosseguindo com as etapas de campo e laboratório visando à delimitação do tema e contemplação da problemática da pesquisa.

\section{$1^{\text {a }}$ Etapa - Levantamento Bibliográfico e Operacionalização da Pesquisa}

$\mathrm{Na}$ primeira etapa da pesquisa buscou-se identificar a área de interesse do estudo, as características do meio físico e o seu recorte espacial, bem como foram definidas as técnicas e métodos operacionais para a etapa seguinte da pesquisa. Foram levantadas as características do meio físico da área e o processo de ocupação da bacia do Santo Antônio. Esta fase da pesquisa foi baseada nos procedimentos habituais de levantamento bibliográfico - levantamentos, leitura, estudos da área, fichamentos, elaboração de textos críticos e artigos.

\section{$2^{\text {a }}$ Etapa - Elaboração do Mapa de Uso do Solo}

A elaboração do mapa de uso do solo da bacia do Santo Antônio deu-se a partir dos dados orbitais de sensoriamento remoto através de imagens de satélite multiespectrais, que trazem informações sobre a bacia hidrográfica e suas características de cobertura e dinâmica da paisagem.

Foram utilizadas como referências imagens CBERS2, resolução espacial $20 \times 20 \mathrm{~m}$ bandas 243 RGB, mosaicada e recortada segundo corte cartográfico 1:250.000, geração $24 / 04 / 2007$, a fonte usada foi da base de dados do SIG-Goiás disponível na Superintendência de Geologia e Mineração.

O procedimento de classificação utilizada no mapa de uso do solo da bacia do Santo Antônio foi à classificação supervisionada, a qual definiu as classes de interesse, onde os pixels das imagens foram enquadrados dentro das classes pré-definidas e calculados parâmetros estatísticos que as descreveram. Este método foi adotado devido ao conhecimento prévio da área de estudos com validações em campo.

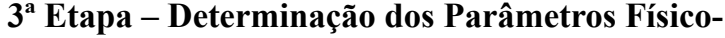 Químicos de Qualidade da Água}

Para a determinação da qualidade da água foram selecionados 11 parâmetros físico-químicos de qualidade das águas para a bacia hidrográfica do Santo Antônio: $\mathrm{pH}$, Condutividade Elétrica (C.E), Sólidos Totais Dissolvidos (STD), Cor, Turbidez, Dióxido de Carbono, Alcalinidade, Nitrato, Cloreto, Amônio e Salinidade. As variações dos parâmetros representam o estado de qualidade da água na bacia do Santo Antônio.

A freqüência de amostragem de água na bacia do Santo Antônio foi definida em uma campanha de campo no período seco e outra no período chuvoso. As amostragens foram realizadas de acordo com o ciclo hidrológico da região.

Aseleção dos pontos de amostragem ocorreu a partir da análise dos seguintes critérios: lançamentos de efluentes ao longo da bacia, incidência de tributários na rede de drenagem, possíveis fontes de poluição identificadas pela avaliação do uso e ocupação do solo e acessibilidade dos pontos selecionados.

A primeira amostragem foi realizada no período chuvoso e para esta foram determinados 9 pontos georeferenciados. Acoleta foi realizada no dia 23/02/2007, apresentando dia ensolarado, sem a presença de nuvens, com temperatura máxima para o dia de $33^{\circ} \mathrm{C}$ registrada pela estação Goiânia do INMET.

A segunda amostragem ocorreu no período seco nos 9 pontos georeferenciados do período chuvoso, acrescidos de 2 pontos. Estes pontos foram incluídos na segunda amostragem em função dos resultados anteriormente obtidos. A coleta do período seco ocorreu no dia 24/09/2007, apresentando dia ensolarado com presença de nuvens e temperatura máxima $26{ }^{\circ} \mathrm{C}$ registrada pela estação Goiânia do INMET.

Os pontos de amostragem dos períodos seco e chuvosos são apresentados na Tabela 1 e espacializados conforme a Figura 2.

As coletas e a preservação das amostras analisadas seguiram as normas técnicas determinadas pela ABNT NBR 9898/1987³, preservadas, acondicionadas em frascos apropriados e enviadas para o laboratório para realização das análises.

Os parâmetros temperatura, $\mathrm{pH}, \quad$ C.E, STD e salinidade, foram avaliados em campo com a utilização 
do aparelho Hach sensION 156. Os demais parâmetros foram analisados no Laboratório de Geoquímica da Universidade de Brasília. As análises de turbidez, cor e dióxido de carbono foram determinadas pelo
Spectofotometro Hach DR 2000. A alcalinidade foi determinada pelo método da titulação potenciométrica. Os íons cloreto, nitrato e amônio foram determinados através de cromatografia líquida com o aparelho Dionex

Tabela 1 - Bacia hidrográfica do Santo Antônio, pontos de amostragem e referência de localização.

\begin{tabular}{|c|c|c|c|c|}
\hline PONTO & OORDENA & AS UTM & ALT. (M) & REFERÊNCIA \\
\hline $\mathrm{P} 1$ & 0679066 & 8139983 & 818 & $\begin{array}{l}\text { Nascente Principal do Santo Antônio - Ponte da Avenida } 21 \text { de Abril, Bairro Nova } \\
\text { Cidade. }\end{array}$ \\
\hline $\mathrm{P} 2$ & 0679404 & 8140514 & 803 & $\begin{array}{l}\text { Próximo ao gabião da Rua Edinom Pereira bairro Nova Cidade, após nascente } \\
\text { secundária do Bairro Tiradentes. }\end{array}$ \\
\hline P3 & 0682637 & 8143015 & 768 & $\begin{array}{l}\text { Final da Rua Maria Arruda, bairro Veiga Jardim IV abaixo da passagem de } \\
\text { ferro para pedestre sobre o Córrego Santo Antônio. }\end{array}$ \\
\hline P4 & 0683439 & 8142683 & 762 & Ponte caída da Avenida escultor Veiga Valle, bairro Veiga Jardim. \\
\hline P5 & 0685679 & 8143498 & 737 & Próximo ao anel viário em frente ao Pólo Industrial Goiás Córrego Santo Antônio. \\
\hline P6 & 0688428 & 8144539 & 723 & Ajusante do Country Club Br 153, Córrego Santo Antônio. \\
\hline P7AM & 0655346 & 8147202 & 772 & Amontante do ponto 7, Córrego do Almeida \\
\hline P7 & 0686272 & 8147083 & 768 & $\begin{array}{l}\text { Avenida São Paulo, bairro Jardim Maria Inês, ajusante da ETE Cruzeiro do Sul, } \\
\text { Córrego do Almeida. }\end{array}$ \\
\hline P7AJ & 0686962 & 8146707 & 763 & Ajusante do ponto 7 Córrego do Almeida \\
\hline P8 & 0690704 & 8145091 & 706 & Pedreira Araguaia, Córrego Santo Antônio. \\
\hline P9 & 0692994 & 8142732 & 693 & Aterro sanitário municipal, Córrego Santo Antônio. \\
\hline
\end{tabular}

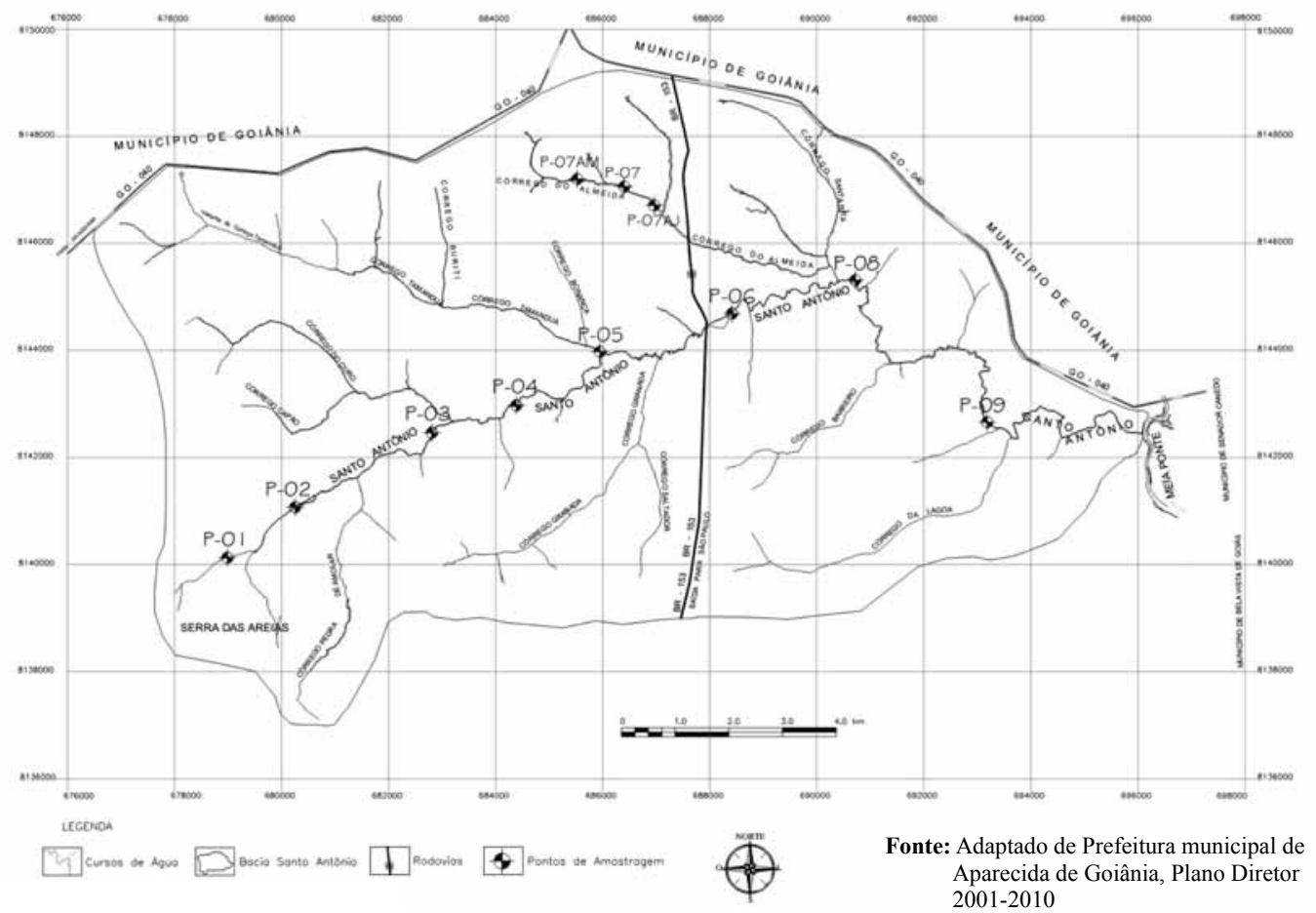

Figura 2: Bacia hidrográfica do Santo Antônio, pontos de amostragem e referência de localização. 
ICS-90.

\section{$4^{\text {a }}$ Etapa - Tratamento dos Dados}

Os dados obtidos na avaliação dos parâmetros físicoquímicos nos períodos seco e chuvoso foram tratados preliminarmente com testes da estatística descritiva paramétrica, sendo utilizados a média harmônica da variação quantitativa dos parâmetros, o desvio padrão $(\sigma)$ dos valores obtidos nos pontos de amostragem, o coeficiente de variação e a definição dos valores “outliers", que identificam as anomalias acima do intervalo (média $+2 \sigma)^{4,5,6}$. Após o tratamento preliminar dos dados, utilizou-se o método da correlação de Spearman (R) entre os parâmetros físico-químicos. Este é um método nãoparamétrico usado em casos que os dados apresentam-se dispersos, com alguns pontos da amostra bem distantes dos demais e quando estes não pertencem a uma escala de medida padrão, porém, possuem uma ordenação.

\section{Resultados e Discussões}

No início da década de 80, Aparecida de Goiânia passou a ser alvo de inúmeros assentamentos promovidos, principalmente, pelo Governo do Estado, atingindo um dos maiores índices de crescimento populacional do Brasil, $19,5 \%$ ao ano ${ }^{7}$.

No período de 1980 a 1998, com a política de assentamento promovida pelo Estado, mais de 80 mil pessoas foram transferidas para áreas públicas estaduais, que foram usadas para assentamentos em Aparecida de Goiânia. A população total em 1980 era de 42.597 habitantes. Em 1991 este contingente aumentou para 178.483 habitantes, sendo que 175.505 residiam em área urbana e apenas 2.821 em área rural ${ }^{8}$.

O crescimento do município de Aparecida de Goiânia deve-se também à proximidade com a capital e especificamente devido às restrições ao parcelamento do solo em Goiânia, tanto que, praticamente, toda a área física do município encontra-se parcelada.

O desafio do ordenamento municipal consiste em compatibilizar as necessidades antrópicas relativas à ocupação e ao uso do solo com a capacidade de suporte do meio físico. O conhecimento das vulnerabilidades e potencialidades ambientais é fator determinante para a construção das propostas de ocupação e uso do solo e a partir de sua análise decorrem as orientações e restrições à apropriação e expansão municipal.

No mapa de uso e ocupação atual da bacia do Córrego Santo Antônio (Figura 3) foram identificadas 4 classes de uso para a bacia, sendo elas: vegetação herbácea, solo exposto, vegetação e área urbana.

A classe vegetação herbácea considera os terrenos desocupados, praças ou parques, as áreas alagadiças, providas de vegetação herbácea e arbustiva, que ocorrem no ambiente urbano, e áreas destinadas a pastagens e terrenos em pousio, com vegetação herbácea e arbustos, que ocorrem em meio rural ${ }^{9}$. Nesta classe estão incluídos fragmentos de área de pastagens, a grande maioria já utilizada para expansão urbana do município. Representam aproximadamente $14,54 \%$ ou $22,90 \mathrm{~km}^{2}$ da área total da bacia, com maior representação a leste da bacia.

Aclasse solo exposto compreende terrenos desprovidos de vegetação, com áreas submetidas a terraplenagem $\mathrm{e}$ áreas recentemente utilizadas para a expansão urbana do município. Constitui-se de loteamentos aprovados e lotes ainda não ocupados, mas com a vegetação completamente removida. Representam 2,05\% ou 3,22 km da área total da bacia.

$\mathrm{Na}$ classe vegetação estão incluídos fragmentos de matas representadas por matas ciliares (originalmente Florestas Estacional semi-decídua). Pode-se observar pelo mapa de uso do solo manchas desse tipo de vegetação seguindo em parte algumas drenagens da bacia sendo que as maiores ocorrências encontram-se próximas ao deságüe no Rio Meia Ponte. Representam aproximadamente $14,16 \%$ ou $22,28 \mathrm{~km}^{2}$ da área total da bacia.

A classe área urbana é representa por todas as áreas ocupadas e edificadas dentro da bacia, incluindo os principais centros comercias do município, os bairros de maiores densidades demográficas, o distrito agro industrial, a estação de tratamento de esgoto Cruzeiro do Sul e as infra-estruturas urbanas. Representam aproximadamente $69,25 \%$ ou $109,00 \mathrm{~km}^{2}$ da área total da bacia. A Tabela 2 apresenta o cálculo de áreas das classes identificadas para o uso do solo no ano de 2007 na bacia do córrego Santo Antônio.

Na bacia do córrego Santo Antônio foram identificados passivos e impactos ambientais relacionados com o uso do solo, decorrentes do processo de ocupação urbana 
ocorrido nas últimas décadas. Em diversos pontos da bacia há lançamentos de efluentes, ocupações no fundo de vale, extração de areia, lançamento de resíduos sólidos, processos erosivos, assoreamentos, remoção da vegetação, dentre outros impactos. Muitos destes impactos são decorrentes do processo desordenado e predatório de uso e ocupação do solo envolvendo muitas vezes áreas impróprias para urbanização $0^{2,6,10,11}$.
Os resultados dos parâmetros físico-químicos dos períodos chuvoso e seco avaliados na bacia hidrográfica do córrego Santo Antônio são demonstrados nas Tabelas 3 e 4 a exceção do ponto 7. Este foi analisado separadamente por ter apresentado as maiores anomalias nos parâmetros avaliados, com variação em torno de 104, impossibilitando o tratamento estatístico utilizado nos demais pontos.

Tabela 2 - Distribuição das classes identificadas no mapa de uso do solo.

\begin{tabular}{ccc}
\hline CLASSES & ÁREA $\left(\mathbf{K M}^{2}\right)$ & ÁREA (\%) \\
\hline Vegetação Herbácea & 22,90 & 14,54 \\
Solo Exposto & 3,22 & 2,05 \\
Vegetação & 22,28 & 14,16 \\
Área Urbana & 109,00 & 69,25 \\
Total & 157,40 & 100 \\
\hline
\end{tabular}

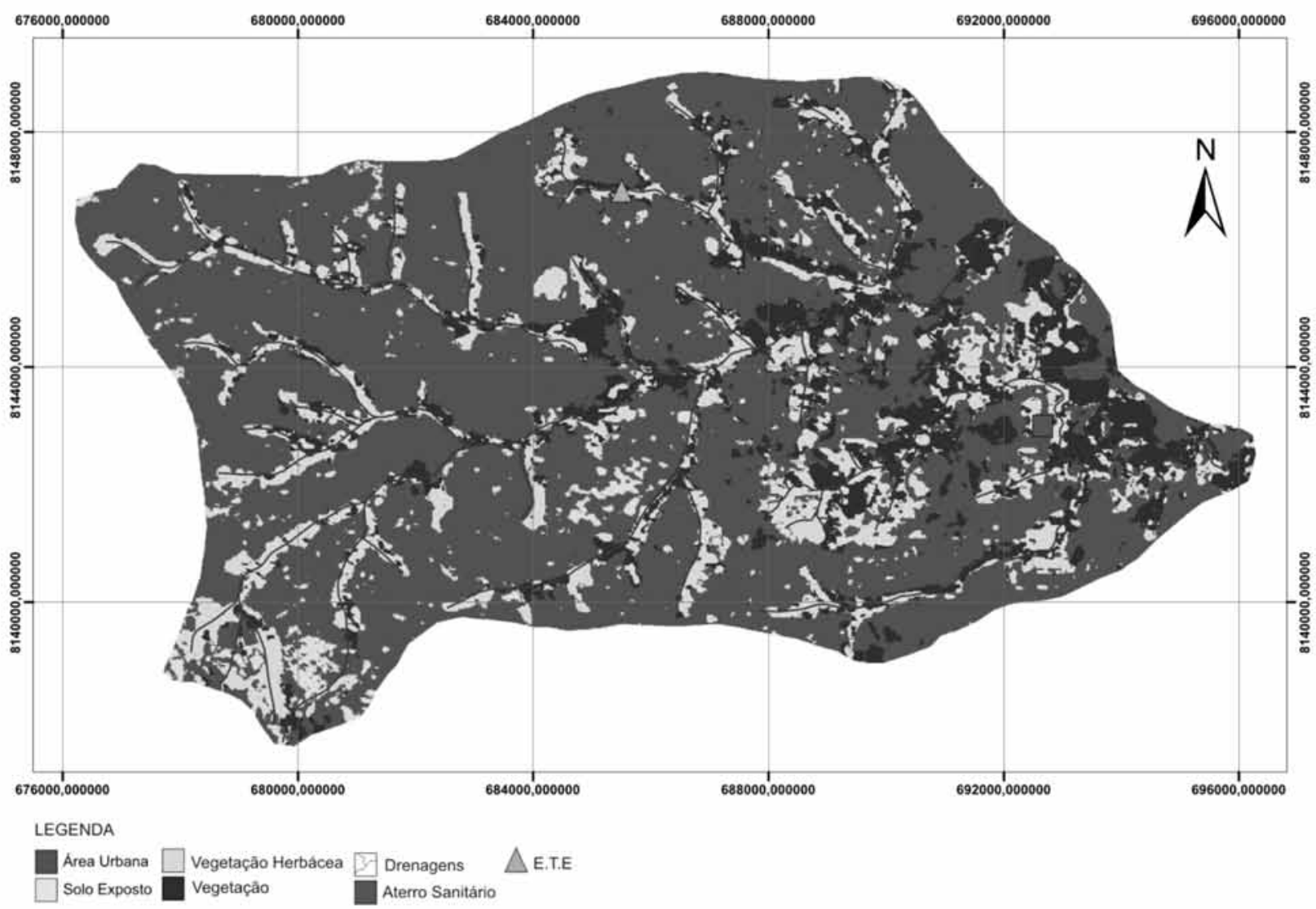

Fonte: SIG - Goiás, base de dados imagens CBERS2, INPE, Classificação Supervisionada.

Figura 3: Uso do solo bacia do córrego Santo Antônio, 2007 


\section{Artigo 8}

Os pontos 1, 2, 3 e 4 estão localizados próximos às áreas de nascente e recebem influência da área urbana. A área que drena para o ponto 5 é influenciada pela área urbana e áreas industriais do município. O ponto 6 está localizada em área urbana, com alta densidade ocupacional, o ponto 8 recebe influência das zonas de

Tabela 3 - Resultados das análises físico-químicas na bacia do Santo Antônio em Aparecida de Goiânia - Período Chuvoso - Coleta 23/02/2007.

\begin{tabular}{|c|c|c|c|c|c|c|c|c|c|c|c|c|c|}
\hline \multirow{2}{*}{ PARÂMETROS } & \multicolumn{8}{|c|}{ PONTOS } & \multirow{2}{*}{ Conama } & \multirow{2}{*}{ Média } & \multirow{2}{*}{$\begin{array}{l}\text { Desvio } \\
\text { Padrão }\end{array}$} & \multirow{2}{*}{$\begin{array}{l}\text { Coeficiente } \\
\text { de Variação }\end{array}$} & \multirow{2}{*}{ Outliers } \\
\hline & P1 & $\mathbf{P 2}$ & P3 & P4 & P5 & P6 & P8 & P9 & & & & & \\
\hline $\mathrm{pH}$ & 6,1 & 6,4 & 6,3 & 6,7 & 6,4 & 6 & 6,6 & 6,1 & $6,0-9,0$ & 6,3 & 0,24 & $3,7 \%$ & 6,8 \\
\hline $\begin{array}{l}\text { Condutividade } \\
\text { Elétrica }(\mu \mathrm{S} / \mathrm{cm})\end{array}$ & 63,5 & 92,2 & 101 & 87,5 & 102,5 & 107,4 & 134,1 & 138,7 & - & 97,9 & 24,4 & $24,9 \%$ & 146,8 \\
\hline $\begin{array}{l}\text { Sólidos Totais } \\
\text { Dissolvidos }(\mathrm{mg} / \mathrm{L})\end{array}$ & 28,6 & 40,2 & 42,2 & 37,5 & 42,8 & 44,7 & 56,8 & 58,7 & 500 & 41,9 & 9,8 & $23,4 \%$ & 61,6 \\
\hline Cor $(\mathrm{uH})$ & 55 & 51 & 261 & 189 & 210 & 531 & 362 & 517 & 75 & 137,3 & 185,8 & $135,3 \%$ & 508,9 \\
\hline Turbidez (uT) & 9 & 10 & 55 & 41 & 53 & 127 & 89 & 131 & 100 & 26,7 & 47,4 & $177,5 \%$ & 121,6 \\
\hline $\begin{array}{l}\text { Dióxido de } \\
\text { Carbono (mg/L) }\end{array}$ & 23,9 & 18 & 22,9 & 22,9 & 22,5 & 23,9 & 21,8 & 23,2 & - & 22,2 & 1,9 & $8,5 \%$ & 26 \\
\hline Alcalinidade $(\mathrm{mg} / \mathrm{L})$ & 24,4 & 27,6 & 32,8 & 31,2 & 31,6 & 32 & 42 & 41,6 & - & 31,9 & 6,1 & $19,2 \%$ & 44,2 \\
\hline Nitrato $(\mathrm{mg} / \mathrm{L})$ & 0,23 & 3,9 & 0,1 & 1,2 & 8,2 & 7,1 & 1,8 & 2,5 & 10 & 0,48 & 3 & $637,5 \%$ & 6,6 \\
\hline Cloreto $(\mathrm{mg} / \mathrm{L})$ & 0,59 & 3,4 & 0,79 & 1,5 & 1,8 & 2,9 & 4,5 & 4,3 & 250 & 1,5 & 1,5 & $101,3 \%$ & 4,6 \\
\hline $\mathrm{NH} 4(\mathrm{mg} / \mathrm{L})$ & 0,21 & 0,17 & 0,6 & 0,46 & 0,52 & 1 & 1,6 & 1,3 & & 0,42 & 0,54 & $128,5 \%$ & 1,5 \\
\hline Salinidade (\%) & - & - & - & - & - & - & - & - & - & - & - & - & - \\
\hline
\end{tabular}

Tabela 4 - Resultados das análises físico-químicas na bacia do Santo Antônio em Aparecida de Goiânia - Período Seco - Coleta 24/09/2007.

\begin{tabular}{|c|c|c|c|c|c|c|c|c|c|c|c|c|c|}
\hline \multirow{2}{*}{ PARÂMETROS } & \multicolumn{8}{|c|}{ PONTOS } & \multirow{2}{*}{ Conama } & \multirow{2}{*}{$\begin{array}{c}\text { Média } \\
\text { Harmônica }\end{array}$} & \multirow{2}{*}{$\begin{array}{r}\text { Desvio } \\
\text { Padrão }\end{array}$} & \multirow{2}{*}{$\begin{array}{l}\text { Coeficiente } \\
\text { deVariação }\end{array}$} & \multirow{2}{*}{ Outliers } \\
\hline & P1 & P2 & P3 & P4 & P5 & P6 & P8 & P9 & & & & & \\
\hline $\mathrm{pH}$ & 7 & 7 & 7,2 & 7,8 & 7,5 & 7,3 & 7,1 & 7 & $6,0-9,0$ & 7,2 & 0,27 & $3,7 \%$ & 7,8 \\
\hline $\begin{array}{l}\text { Condutividade } \\
\text { Elétrica }(\mu \mathrm{S} / \mathrm{cm})\end{array}$ & 67,1 & 374 & 792 & 192 & 255 & 315 & 1547 & 433 & - & 234,6 & 474,8 & $202,3 \%$ & 1184,2 \\
\hline $\begin{array}{l}\text { Sólidos Totais } \\
\text { Dissolvidos }(\mathrm{mg} / \mathrm{L})\end{array}$ & 31,6 & 180 & 387 & 92 & 122 & 152 & 769 & 209 & 500 & 111,8 & 236,9 & $211,8 \%$ & 585,7 \\
\hline Cor $(\mathrm{uH})$ & 17 & 11 & 10 & 9 & 11 & 13 & 22 & 40 & 75 & 13,3 & 10,3 & $77,6 \%$ & 34 \\
\hline Turbidez (uT) & 5 & 3 & 8 & 6 & 8 & 14 & 7 & 8 & 100 & 6 & 3,2 & $53,1 \%$ & 12,4 \\
\hline Dióxido de Carbono (mg/L) & 1,7 & 1,7 & 0 & 0 & 0 & 0 & 0 & 1,7 & - & - & 0,91 & - & - \\
\hline Alcalinidade (mg/L) & 41,6 & 31,2 & 54,4 & 41,6 & 46 & 59,2 & 81,2 & 60 & - & 48,1 & 15,3 & $31,9 \%$ & 78,9 \\
\hline Nitrato $(\mathrm{mg} / \mathrm{L})$ & 0,3 & 2,2 & 0,6 & 0,4 & 1,1 & 0,5 & 1,5 & 1,9 & 10 & 0,66 & 0,73 & $110,6 \%$ & 2,1 \\
\hline Cloreto $(\mathrm{mg} / \mathrm{L})$ & 4,5 & 8,4 & 8,2 & 8,4 & 8,3 & 9 & 14,9 & 16,7 & 250 & 8,6 & 3,9 & $45,7 \%$ & 16,5 \\
\hline $\mathrm{NH}_{4}(\mathrm{mg} / \mathrm{L})$ & 0,05 & 0,04 & 0,18 & 0,04 & 0,36 & 0,55 & 2,4 & 2,2 & & 0,09 & 1 & $1111,1 \%$ & 2 \\
\hline Salinidade (\%) & 0 & 0,1 & 0,4 & 0 & 0,1 & 0,2 & 0,8 & 0,2 & - & - & 0,26 & - & - \\
\hline
\end{tabular}


pedreiras e o pontos 9 está localizado na área de influência do aterro sanitário municipal.

Os pontos avaliados apresentaram $\mathrm{pH}$ levemente ácido variando de 6,05 a 6,72 com uma média harmônica de 6,36 e um baixo coeficiente de variação $(3,37 \%)$ e não apresentaram valores outliers para o período chuvoso. No período seco houve uma pequena alteração nesse parâmetro apresentando uma média harmônica de 7,29, porém ao longo dos pontos de amostragens manteve um baixo coeficiente de variação $(3,70 \%)$ e, somente o ponto 4 apresentou valor pouco acima do outliers, mas dentro das recomendações da Resolução do CONAMA (Figura 4).

A avaliação do $\mathrm{pH}$ demonstra um aumento da acidez das águas durante o período chuvoso, conseqüência da precipitação de materiais em suspensão na atmosfera e

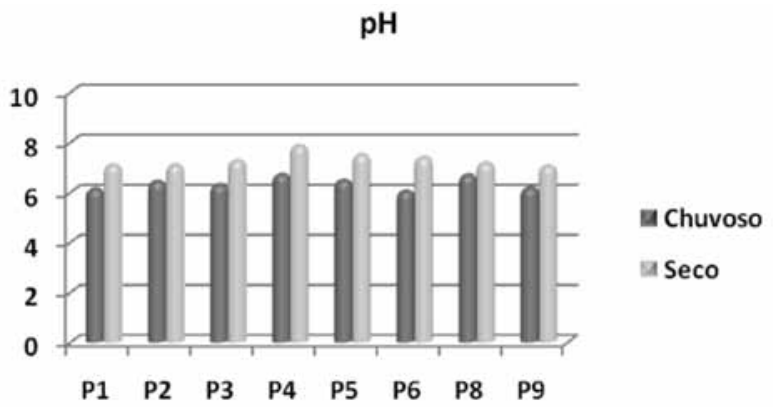

Figura 4: Variação sazonal do pH na bacia do Santo Antônio.

o lançamento das águas pluviais da rede de drenagem do município.

Os parâmetros C.E e S.T.D tendem a diminuir suas concentrações no período chuvoso em todos os pontos, apresentando média harmônica de $97,97 \mu \mathrm{S} / \mathrm{cm}$ e $41,97 \mathrm{mg} / \mathrm{L}$, respectivamente.

No período seco a C.E oscilou de $67,1 \mu \mathrm{S} / \mathrm{cm}$ a $1.547 \mu \mathrm{S} / \mathrm{cm}$, com média harmônica de 234,60 $\mu \mathrm{S} / \mathrm{cm}$ e alto coeficiente de variação $202,3 \%$ (Figuras 5 e 6 ). Os valores outliers desses parâmetros referem-se ao ponto 8. Entretanto, os valores de STD não ultrapassaram o estabelecido pelo CONAMA (Tabela 5). Esta variação nos valores dos parâmetros C.E e STD é conseqüência direta dos diferentes uso do solo na bacia intensificada pela ocupação urbana (ponto 3) e recebimento da contribuição do afluente córrego do Almeida (ponto 8).

Da análise dos gráficos dos parâmetros C.E e S.T.D é possível visualizar a correlação entre estes parâmetros

\section{C.E $(\mathrm{mS} / \mathrm{cm})$}

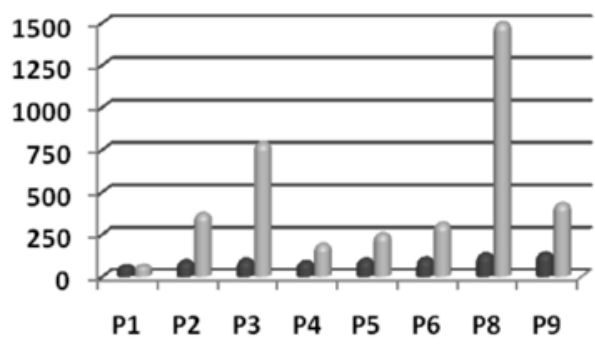

Chuvoso

回Seco

$\operatorname{STD}(\mathrm{mg} / \mathrm{L})$

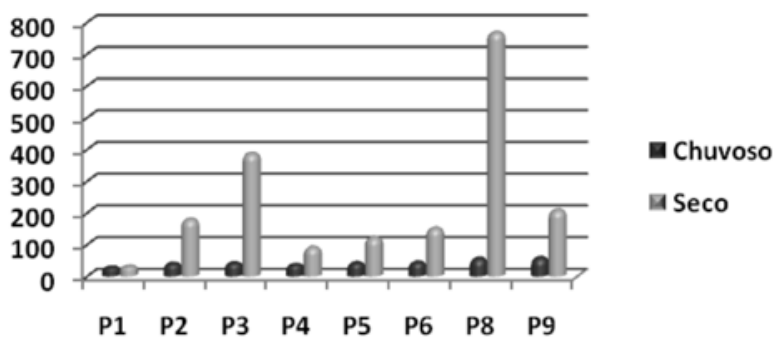

Figuras 5 e 6: Variação sazonal da condutividade elétrica e dos sólidos totais dissolvidos na bacia do Santo Antônio.

apresentando gráficos com distribuição qualitativa semelhante entre os pontos.

O estudo Caracterização do Meio Físico, dos Recursos Minerais e Hídricos do Município de Aparecida de Goiânia $^{2}$, realizou em 2005 uma análise dos parâmetros físico-químicos pH, C.E e S.T.D, com amostragens no córrego do Almeida e na área da pedreira Araguaia no córrego Santo Antônio, para o período chuvoso. Em comparação ao presente trabalho os resultados obtidos por este estudo são semelhantes aos atuais para os

Tabela 5 - Resultados das análises físico-químicas realizadas pelo estudo Caracterização do Meio Físico, dos Recursos Minerais e Hídricos do Município de Aparecida de Goiânia.

\begin{tabular}{cccccc}
\hline REFERÊNCIA DE LOCALIZAÇÃO & pH & S.T.D & C.E & COORDENADAS UTM \\
\hline Córrego Almeida - BR 153 & 7,5 & 279 & 550 & $0687596 \quad 8146122$ \\
Córrego St. Antônio - Pedreira Araguaia & 8,14 & 92 & 182 & 06904818145128 \\
\hline
\end{tabular}

Fonte: Adaptado de RODRIGUES, A.P. (coord.) Caracterização do Meio Físico, dos Recursos Minerais e Hídricos do Município de Aparecida de Goiânia. Goiânia: Superintendência de Geologia e Mineração, 2005.

períodos chuvoso, nas áreas próximas aos pontos 5, 7 e 8 
conforme demonstra a Tabela 5 abaixo.

Em relação ao parâmetro cor, os valores oscilaram entre $51 \mathrm{uH}$ e $531 \mathrm{uH}$ no período chuvoso. Nos pontos 1 e 2 inseridos na área da nascente não ultrapassaram as recomendações da resolução 357/05 do CONAMA. Já nos demais pontos, locados em áreas urbanas com diferentes usos do solo ultrapassaram os V.M.P, indicando a presença de sólidos em suspensão e de matéria orgânica.

A média harmônica do parâmetro cor nesse período foi de 137,3 uH e coeficiente de variação de 135,3\%. No período seco houve uma redução nos quantitativos deste parâmetro em todos os pontos de amostragem, mantendo-se em conformidade com a resolução 357/05 do CONAMA, apresentando média harmônica de 13,3 uH e coeficiente de variação de 77,6\% (Figura 7).

No período chuvoso o parâmetro turbidez apresentou média harmônica de 28,3 uT. No ponto 6 , localizado a jusante do Country Club na BR 153 e no ponto 9 localizado próximo ao aterro sanitário municipal, os valores de turbidez ultrapassaram os V.M.P pela resolução 357/05 do CONAMA com valores de 129 uT e 131 uT, respectivamente. Os pontos 6 e 9 possuem corredeiras e quedas d'água que podem proporcionar esse aumento da turbidez na época chuvosa, por meio do aumento de material em suspensão possivelmente originários da área de influência dos usos do solo indicados (Figura 8). No período seco, assim como ocorreu com o parâmetro cor, houve uma redução dos valores para a turbidez, apresentando média harmônica de 6,02 uT.

Os dados obtidos nessa avaliação para os parâmetros cor e turbidez apresentaram, principalmente na época seca, valores que se aproximaram dos obtidos pelo programa de monitoramento ambiental do Rio Meia Ponte executado pela Agência Goiana de Meio Ambiente no ponto de monitoramento RMP PT 16 em 19/06/2007 correspondente ao período seco ${ }^{12}$. Esse ponto localizase próximo a divisa entre os municípios de Goiânia e Aparecida de Goiânia com influência de área urbana e de áreas verdes de pequenas propriedades rurais.

Durante a avaliação nos períodos seco e chuvoso os teores de nitrato, cloreto e amônia mantiveram-se em conformidade com os V.M.P pela resolução 357/05 do CONAMA (Tabela 3 e 4).

O nitrato e o cloreto apresentam maiores concentrações na época chuvosa. As possíveis fontes de alterações nesses parâmetros são os esgotos domésticos sanitários

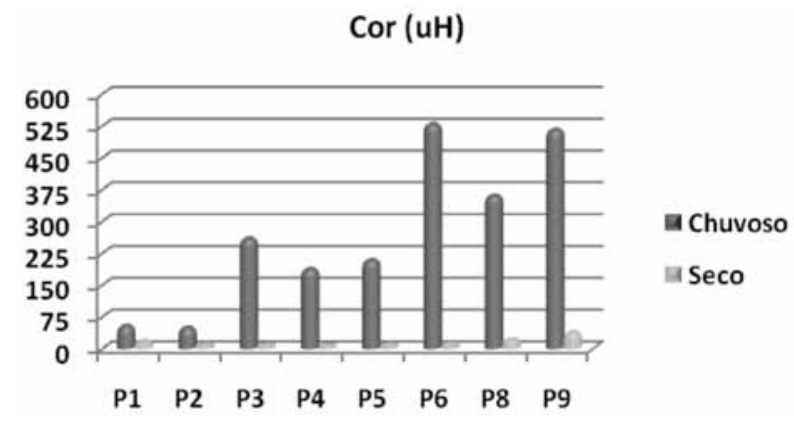

Turbidez (UT)

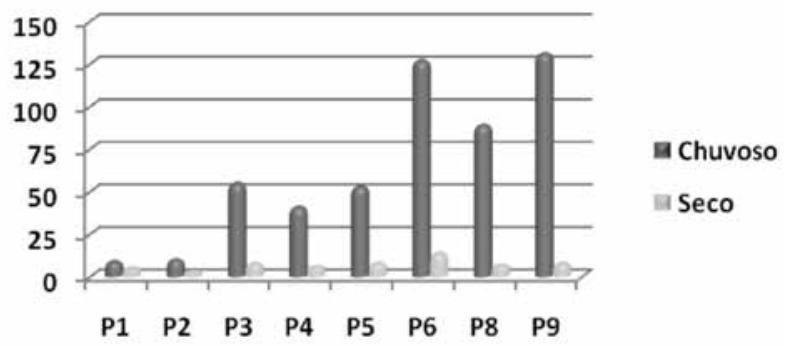

Figuras 7 e 8: Variação sazonal da Cor e Turbidez na bacia do Santo Antônio.

oriundos da área urbana e/ou fertilizantes de pequenas chácaras nos fundos de vale (Figuras 9 e 10).

O nitrato e o cloreto apresentam maiores concentrações na época chuvosa. As possíveis fontes de alterações nesses parâmetros são os esgotos domésticos sanitários oriundos da área urbana e/ou fertilizantes de pequenas chácaras nos fundos de vale (Figuras 9 e 10).

No período chuvoso, o nitrato, cloreto e o amônio (Figuras 9,10,11), apresentaram valores outliers, para os pontos 5 e 6, contudo, todos dentro da resolução 357/05 do CONAMA. Estes valores indicam que poluentes com altas concentrações de nitrato ao atingirem as águas dos rios têm seus teores diluídos, podendo chegar a baixas concentrações. Para o período seco o nitrato não apresentou valores outliers. Para o período seco os valores do nitrato e cloreto ficaram acima da média de outras áreas localizadas na região metropolitana de Goiânia ${ }^{1}$.

Os parâmetros dióxido de carbono, alcalinidade e salinidade não possuem referência dentro da resolução 357/05 do CONAMA. Os valores de dióxido de carbono 
no período chuvoso oscilaram entre 18 e $23,9 \mathrm{mg} / \mathrm{L}$ com média harmônica de $22,2 \mathrm{mg} / \mathrm{L}$ e baixo coeficiente de variação $(8,5 \%)$. O dióxido de carbono presente nas precipitações é dissolvido no corpo hídrico resultando em ácido carbono, com conseqüência direta na redução
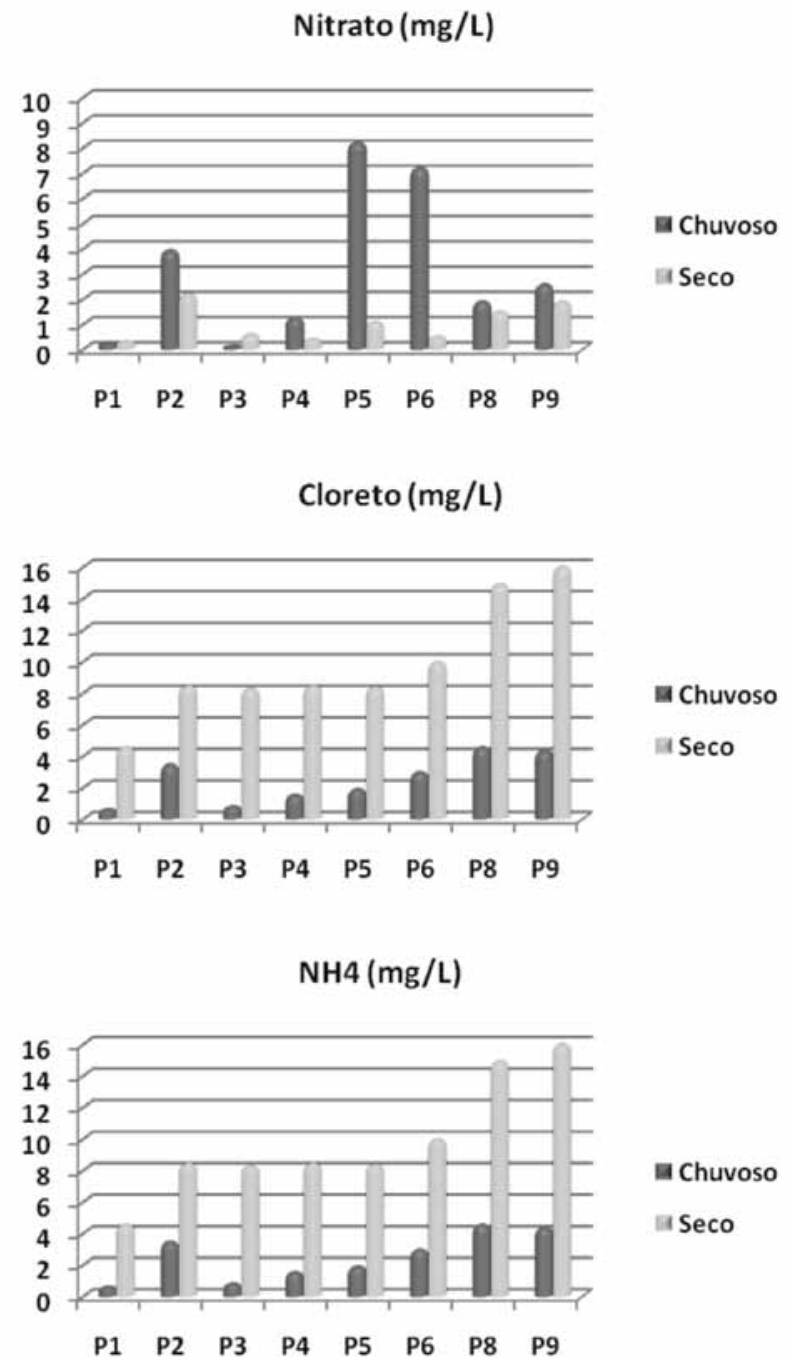

Figuras 9, 10 e 11: Variação sazonal do $\mathrm{CO} 2$, da Alcalinidade e da Salinidade na bacia do Santo Antônio.

do $\mathrm{pH}$ no período chuvoso. No período seco observouse uma redução considerável nos valores para este parâmetro (Figura 12).

A alcalinidade variou de 24,4 a $42 \mathrm{mg} / 1$ no período chuvoso perfazendo uma média harmônica de $31,9 \mathrm{mg} / 1$. No período seco assim como a maioria dos parâmetros de qualidade avaliados, percebe-se o aumento nos valores deste parâmetro variando de 31,2 a $81,2 \mathrm{mg} / 1$ com média de $48,1 \mathrm{mg} / \mathrm{l}$ (Figura 13).

O parâmetro salinidade não foi detectado no período
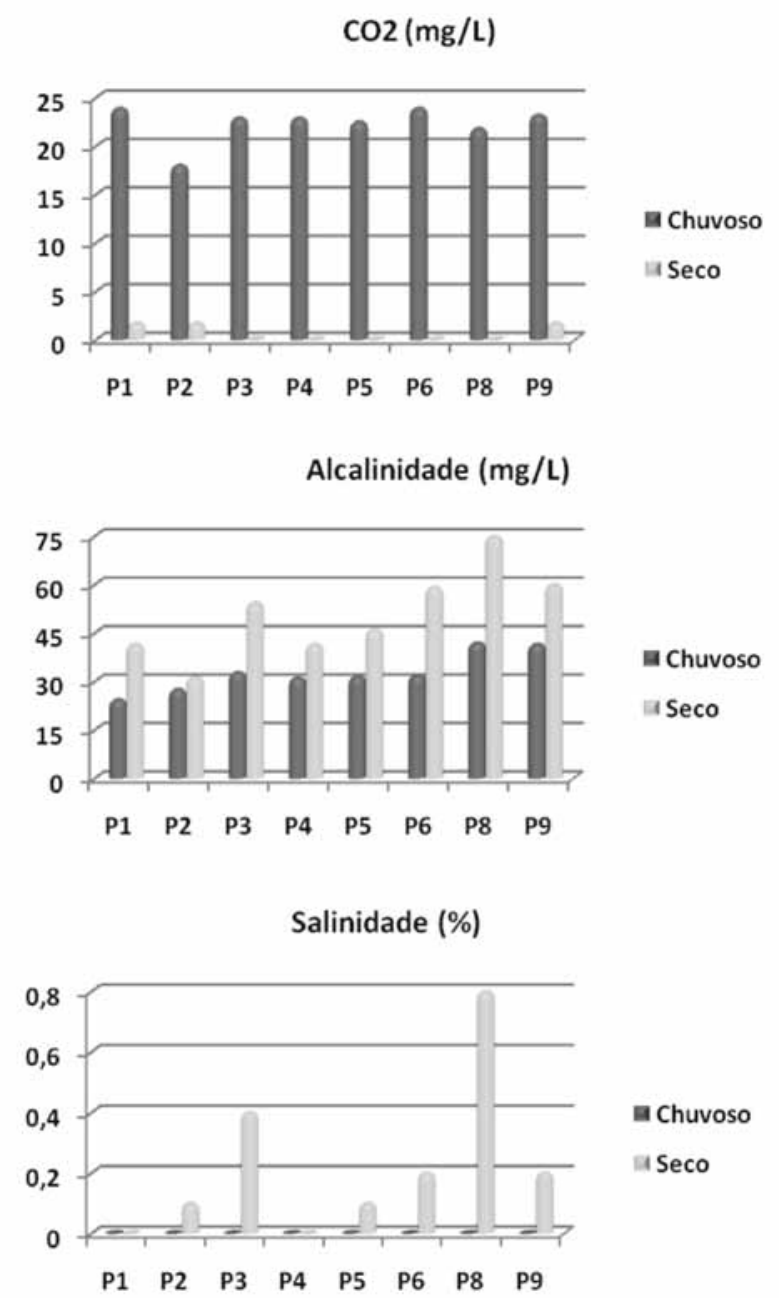

Figuras 12, 13 e 14: Variação sazonal do $\mathrm{CO} 2$, da Alcalinidade e da Salinidade na bacia do Santo Antônio.

chuvoso. No período seco observa-se a presença de salinidade. Os pontos 1 e 4 não apresentam salinidade (Figura 14).

O ponto 7, localizado no córrego do Almeida, foi analisado separadamente em função dos valores obtidos nos parâmetros amostrados. Para o período seco, foi realizado um adensamento na amostragem a jusante e a montante da área de influência do ponto (Tabela 6).

Os pontos 7AM, 7 e $7 \mathrm{AJ}$ apresentaram as maiores 
anomalias nos parâmetros diretamente relacionados a presença de esgotos domésticos sanitários, tanto no período chuvoso quanto no período seco, em função da influência da E.T.E Cruzeiro do Sul. As concentrações

Tabela 6 - Resultados das análises físico-químicas na bacia do Santo Antônio em Aparecida de Goiânia Ponto de avaliação 7 chuvoso/7AM seco/7 seco/7AJ seco.

\begin{tabular}{|c|c|c|c|c|c|}
\hline \multirow{2}{*}{ PARÂMETROS } & \multicolumn{4}{|c|}{ PONTOS } & \multirow{2}{*}{ CONAMA } \\
\hline & P7 Chuva & P7-AM Seco* & P7 Seco & P7-AJ Seco* & \\
\hline $\mathrm{pH}$ & 6,7 & 7,1 & 6,9 & 7 & $6,0-9,0$ \\
\hline Condutividade Elétrica $(\mu \mathrm{S} / \mathrm{cm})$ & 350 & 43600 & 21600 & 34000 & - \\
\hline Sólidos Totais Dissolvidos (mg/L) & 149,7 & 27000 & 12490 & 20500 & 500 \\
\hline Cor $(\mathrm{uH})$ & 162 & 53 & 45 & 45 & 75 \\
\hline Turbidez (uT) & 55 & 135 & 90 & 110 & 100 \\
\hline Dióxido de Carbono (mg/L) & 88 & 0 & 1,7 & 1,7 & - \\
\hline Alcalinidade $(\mathrm{mg} / \mathrm{L})$ & 104,8 & 211 & 186 & 181 & - \\
\hline Nitrato $(\mathrm{mg} / \mathrm{L})$ & 0,42 & 3 & 1,5 & 0,7 & 10 \\
\hline Cloreto $(\mathrm{mg} / \mathrm{L})$ & 21,8 & 39,4 & 30,9 & 32,6 & 250 \\
\hline $\mathrm{NH}_{4}(\mathrm{mg} / \mathrm{L})$ & 2,7 & 16,5 & 15,1 & 18,8 & \\
\hline Salinidade (\%) & 0,1 & 28,1 & 13 & 21,3 & - \\
\hline
\end{tabular}

para o período seco são maiores, com elevações exponenciais na ordem de 103, em comparação com o período chuvoso.

Assim como os demais pontos avaliados na bacia do córrego Santo Antônio, a condição sanitária é agravada no período seco, apresentando as maiores elevações nos parâmetros de qualidade em função da redução da vazão das drenagens, favorecendo a concentração dos elementos.

$\mathrm{O}$ parâmetro $\mathrm{pH}$ manteve a média de variação encontrada nos demais pontos avaliados na bacia nos períodos chuvoso e seco, dentro das recomendações da resolução 357/05 do CONAMA (Fig 15).

Os STD e a C.E, apresentaram no período chuvoso valores acima da média dos demais pontos avaliados. Destaca-se o período seco para STD que variaram de 27.000 no ponto 7AM próximo ao lançamento da ETE Cruzeiro do Sul e 12.490 no ponto 7 , enquanto a C.E variou de 43.600 no ponto $7 \mathrm{AM}$ a 21.600 no ponto 7 (Figuras 16 e 17). Estes parâmetros indicam a presença de esgotos sanitários domésticos concentrados no período seco, devido não haver a diminuição na vazão do lançamento dos efluentes da ETE Cruzeiro do Sul, porém há a redução da vazão do córrego do Almeida, favorecendo a concentração dos elementos.

Os parâmetros cloreto e alcalinidade apresentaram variações quantitativas maiores que a média dos demais pontos avaliados na bacia do Santo Antônio, para o período chuvoso. Para o período seco as variações são intensificadas (Figuras 18 e 19).

O nitrato manteve-se dentro da média encontrada nos demais pontos avaliados na bacia, nos período chuvoso e seco e dentro das recomendações da resolução do 357/05 do CONAMA (Figura 20).

O dióxido de carbono apresentou comportamento semelhante aos demais pontos, com valores maiores no 
período chuvoso e conseqüente redução no período seco, por estar relacionado com os índices de precipitação (Figura 21).

O parâmetro turbidez não ultrapassou a resolução 357/05 do CONAMA no período chuvoso. No período seco os pontos P7AM e P7AJ, apresentaram valores acima dos V.M.P da resolução (Figura 23). Apenas para o período chuvoso o parâmetro cor apresentou valor acima das recomendações da resolução 357/05 do CONAMA (Figura 22).

Foi constatada salinidade no período chuvoso com valor de $0,1 \%$. Para o período seco observa-se o aumento significativo nos valores de salinidade para estes pontos, variando de $13 \%$ no ponto 7 a $28,1 \%$ no ponto 7AM.

O parâmetro amônio, apresentou valores acima

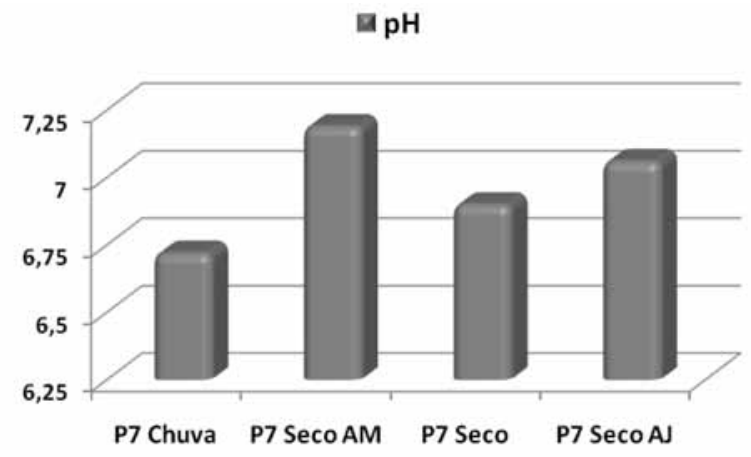

da média dos demais pontos avaliados na bacia com $2,7 \mathrm{mg} / \mathrm{L}$ no período chuvoso e variando de $15,1 \mathrm{mg} / \mathrm{L}$ a $18,8 \mathrm{mg} / \mathrm{L}$ no período seco.

É importante ressaltar o processo de depuração na bacia verificado nesta avaliação. Após as anomalias identificadas nos pontos 7AM, 7 e 7AJ no córrego do Almeida, os pontos em seqüência a esses no córrego Santo Antônio (pontos 8 e 9) demonstram redução significativa nos valores dos parâmetros físico-químicos em ambos os períodos. Após o tratamento estatístico paramétrico dos dados, utilizou-se a correlação de Spearman (R) entre parâmetros físico-químicos. Este é um método nãoparamétrico usado em casos que os dados apresentam-se dispersos, com alguns pontos da amostra bem distantes dos demais e não pertencentes a uma escala de medida

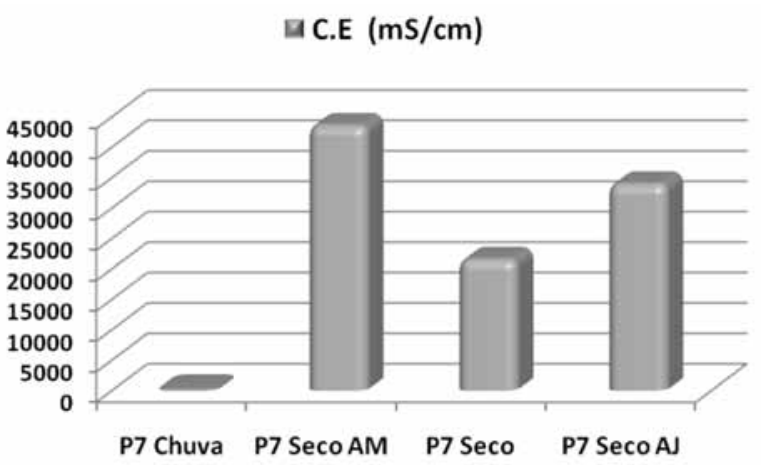

\section{回 STD (mg/L)}

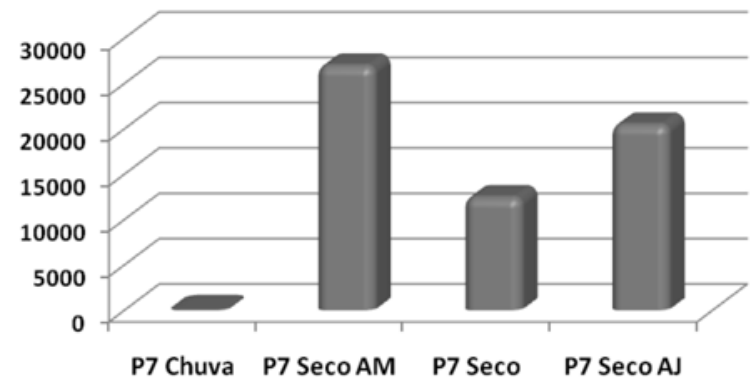

Figuras 15, 16 e 17: Variação sazonal dos parâmetros físico-químicos: pH, C.E ( $\mu \mathrm{S} / \mathrm{cm})$ e S.T.D (mg/l), no córrego do Almeida. 


\section{Artigo 8}

padrão, porém com uma ordenação. Os resultados são apresentados nas Tabelas 7 e 8 , para os períodos chuvoso

回 STD (mg/L)

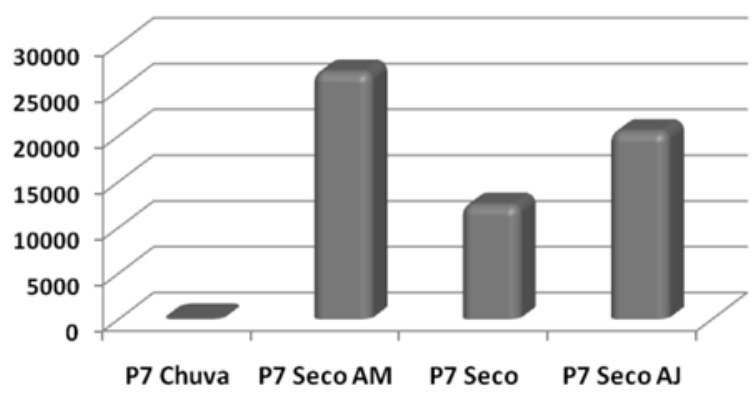

e seco.

Dentre as correlações dos parâmetros avaliados no

Figuras 18 e 19: Variação sazonal dos parâmetros físico-químicos: Cloreto e Alcalinidade, no córrego do Almeida.
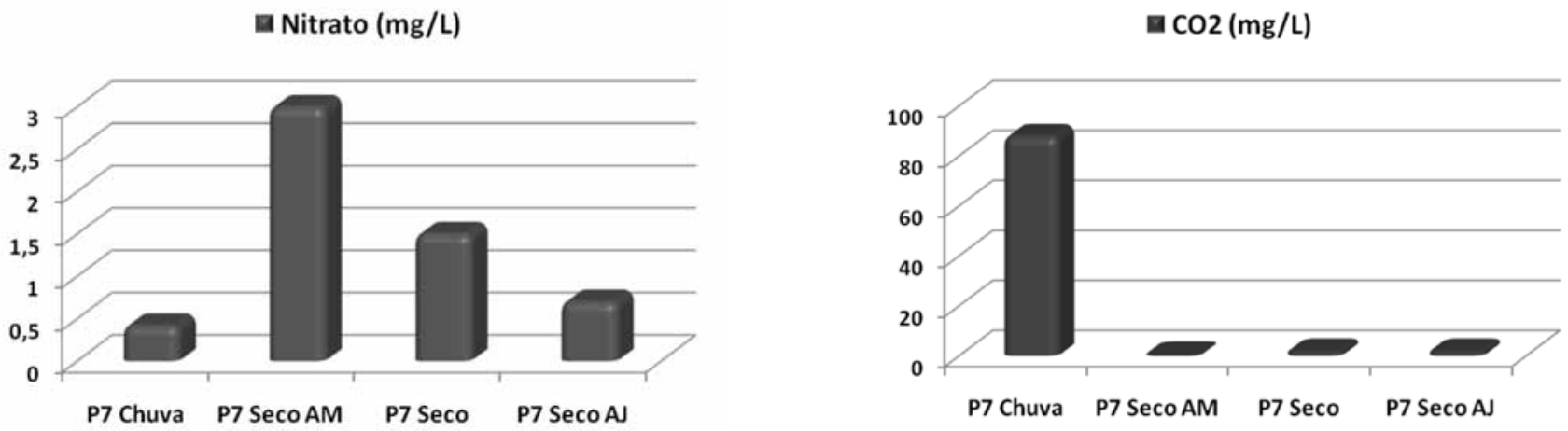

Figuras 20 e 21: Variação sazonal dos parâmetros físico-químicos: nitrato e dióxido de carbono, no córrego do Almeida.
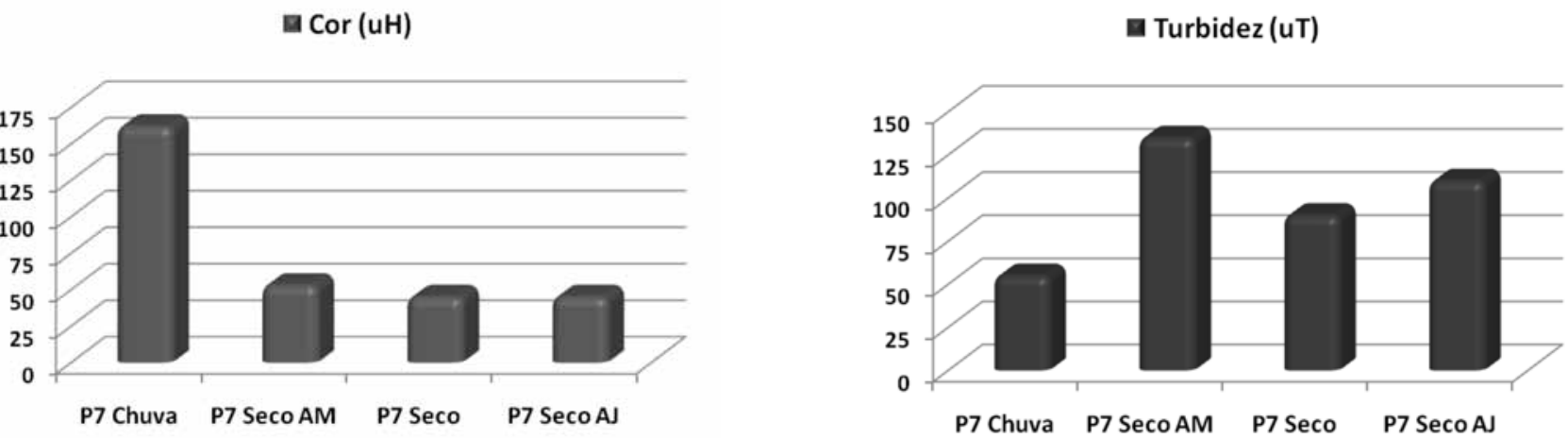

Figuras 22 e 23: Variação sazonal dos parâmetros físico-químicos: Cor (uH) e Turbidez (uT), no córrego do Almeida. 
国H $(\mathrm{mg} / \mathrm{L})$

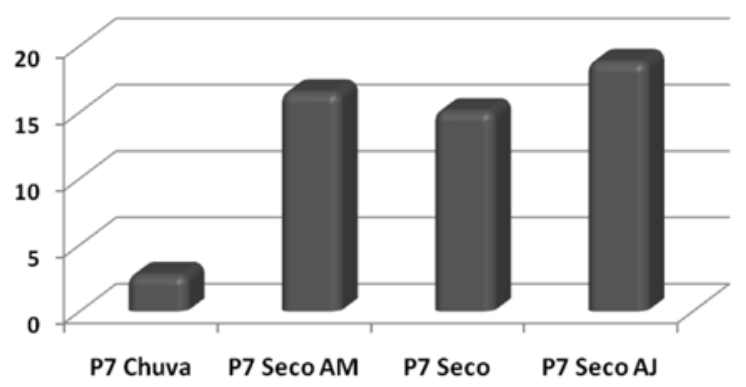

四 Salinidade (\%)

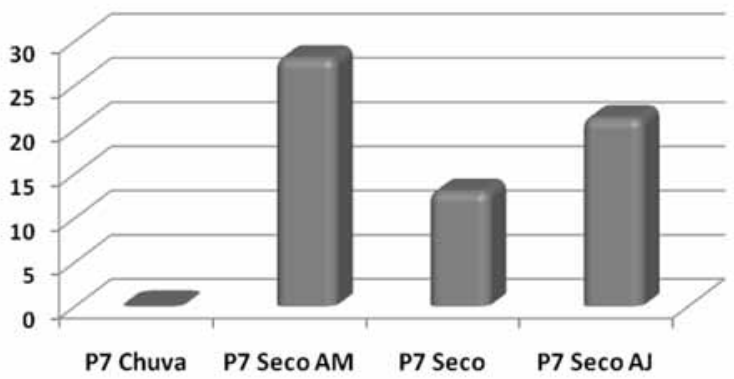

Figuras 24 e 25: Variação sazonal dos parâmetros físico-químicos: Amônio (mg/l) e salinidade ( \%), no córrego do Almeida.

Tabela 7 - Matriz de correlação de Spearman entre parâmetros físico-químicos, nas águas da Bacia do Santo Antônio, período chuvoso. Apenas as correlações com significância $\mathrm{p}<0,05$ são apresentadas.

\begin{tabular}{|c|c|c|c|c|c|c|c|c|c|c|}
\hline & $\mathrm{pH}$ & C.E & S.T.D & Cor & Turbidez & $\mathrm{CO}$ & Alcalinidade & Nitrato & Cloreto & $\mathrm{NH}_{4}$ Salinidade \\
\hline $\mathrm{pH}$ & 1 & & & & & & & & & \\
\hline C.E & * & 1 & & & & & & & & \\
\hline S.T.D & $*$ & 1 & 1 & & & & & & & \\
\hline Cor & $*$ & $*$ & $*$ & 1 & & & & & & \\
\hline Turbidez & $*$ & 0,81 & 0,81 & 0,89 & 1 & & & & & \\
\hline $\mathrm{CO}_{2}$ & $*$ & $*$ & $*$ & $*$ & $*$ & 1 & & & & \\
\hline Alcalinidade & $*$ & 0,91 & 0,91 & $*$ & 0,77 & $*$ & 1 & & & \\
\hline Nitrato & $*$ & $*$ & $*$ & * & $*$ & $*$ & * & 1 & & \\
\hline Cloreto & $*$ & 0,85 & 0,85 & $*$ & $*$ & $*$ & 0,73 & $*$ & 1 & \\
\hline $\mathrm{NH}_{4}$ & $*$ & 0,91 & 0,91 & $*$ & 0,8 & $*$ & 0,96 & $*$ & 0,7 & 1 \\
\hline Salinidade & $*$ & $*$ & $*$ & * & $*$ & $*$ & $*$ & $*$ & $*$ & 1 \\
\hline
\end{tabular}

Tabela 7 - Matriz de correlação de Spearman entre parâmetros físico-químicos, nas águas da Bacia do Santo Antônio, período chuvoso. Apenas as correlações com significância $\mathrm{p}<0,05$ são apresentadas.

\begin{tabular}{|c|c|c|c|c|c|c|c|c|c|c|c|}
\hline & $\mathrm{pH}$ & C.E & S.T.D & Cor & Turbidez & $\mathrm{CO}_{2}$ & Alcalinidade & Nitrato & Cloreto & $\mathrm{NH}_{4}$ & Salinidade \\
\hline $\mathrm{pH}$ & 1 & & & & & & & & & & \\
\hline C.E & $*$ & 1 & & & & & & & & & \\
\hline S.T.D & $*$ & 1 & 1 & & & & & & & & \\
\hline Cor & $*$ & 0,72 & 0,72 & 1 & & & & & & & \\
\hline Turbidez & $*$ & 0,72 & 0,72 & 0,67 & 1 & & & & & & \\
\hline $\mathrm{CO}_{2}$ & $*$ & * & $*$ & $*$ & $*$ & 1 & & & & & \\
\hline Alcalinidade & $*$ & 0,86 & 0,86 & 0,84 & 0,86 & * & 1 & & & & \\
\hline Nitrato & * & 0,63 & 0,63 & $*$ & $*$ & * & * & 1 & & & \\
\hline Cloreto & $*$ & 0,81 & 0,81 & 0,81 & 0,73 & $*$ & 0,85 & 0,6 & 1 & & \\
\hline $\mathrm{NH}_{4}$ & $*$ & 0,83 & 0,83 & 0,88 & 0,85 & * & 0,95 & $*$ & 0,84 & 1 & \\
\hline Salinidade & $*$ & 0,97 & 0,97 & 0,75 & 0,82 & $*$ & 0,92 & $*$ & 0,8 & 0,89 & 1 \\
\hline
\end{tabular}


período chuvoso e seco, os S.T.D e C.E correlacionam com os parâmetros cor, turbidez, dióxido de carbono, alcalinidade, nitrato, cloreto, amônio e salinidade. Destaca-se para o período seco uma forte correlação $(\mathrm{R}=0,97)$ do parâmetro salinidade com os parâmetros C.E e S.T.D. Estes resultados sugerem a contribuição das atividades domésticas e rurais conforme os usos do solo na bacia.

Os parâmetros cor e turbidez apresentam forte correlação ( $\mathrm{R}=0,89)$, no período chuvoso, por estarem diretamente ligados a quantidade de materiais suspensos na água, carreados nesse período. Os mesmos parâmetros não apresentam forte correlação no período seco.

No período seco observa-se mais claramente a forte correlação entre os parâmetros do que no período chuvoso. Isso indica que a influência das zonas de uso do solo e ocupação é maior no período de seca em conseqüência da concentração dos elementos na água.

\section{Considerações Finais}

O município de Aparecida de Goiânia possui diversos desajustes de planejamento urbanístico, econômico, social e ambiental, intensificados ao longo de sua história. A sua ocupação ocorreu de forma desordenada e predatória, envolvendo em muitos casos áreas impróprias para urbanização.

$\mathrm{O}$ inadequado processo de uso e ocupação do solo especialmente na bacia do córrego Santo Antônio, contribuiu de forma significativa para as alterações na qualidade da água, seja por áreas de preservação permanente desprovidas de cobertura vegetal, ou pelos lançamentos de efluentes in-natura e resíduos nas drenagens da bacia.

A avaliação físico-química da qualidade da água na bacia hidrográfica do Santo Antônio nas épocas seca e chuvosa, mostrou primeiramente que a situação da qualidade da água é agravada durante o período seco, pela concentração dos poluentes.

No período chuvoso constatou o carreamento do solo para o leito do Santo Antônio e seus tributários, adicionado a este fator teremos a presença de resíduos sólidos em suas vertentes que também são carreados ao leito, estes fatores provocam as alterações nos parâmetros de qualidade da água.
Deve-se considerar que apesar dos pontos avaliados estarem na zona de preservação permanente, conforme a lei de zoneamento de Aparecida de Goiânia (Lei complementar $n^{\circ}$. 005/2002), o mapa de uso do solo elaborado através da imagem CBERS2, 2007, apresenta pela classificação supervisionada um total de área de vegetação $22,28 \mathrm{~km}^{2}$, correspondente a $14,16 \%$ do total da área da bacia. Está vegetação está distribuída em fragmentos, dispersos que não acompanham em sua maioria os corpos de água da bacia. Conseqüentemente os pontos avaliados recebem influência direta dos passivos ambientais, decorrentes do processo histórico de uso e ocupação do solo.

Os pontos selecionados em áreas com maior ocupação urbana, ou próximos a atividades que apresentam maior potencial poluidor ETE Cruzeiro do Sul, e o Aterro Sanitário, demonstraram quantitativamente maiores valores nos parâmetros de qualidade avaliados, em comparação aos pontos selecionados próximos a nascente.

Alguns pontos ultrapassaram as recomendações da resolução 357/05 do CONAMA. Este fator é constatado nos dois períodos do ciclo hidrológico, embora o $\mathrm{pH}$ não sofra grandes variações.

Verificou-se também que os pontos selecionados no córrego do Almeida, recebem alta carga de poluentes oriundos da ETE Cruzeiro do Sul, e que as concentrações desta carga poluidora é maior no período de seca. Foi observado o potencial depurador na bacia do Santo Antônio nos pontos a jusantes localizados no córrego Santo Antônio e é perceptível uma redução dos valores quantitativos dos parâmetros principalmente a condutividade elétrica e os sólidos totais dissolvidos.

Os resultados obtidos nas análises de condutividade elétrica, sólidos totais dissolvidos, cor, turbidez, salinidade e nitrato nos períodos do ciclo hidrológico estudado apresentaram-se acima da média de outros estudos na região, indicando a influência de efluentes domésticos e aponta o possível comprometimento da qualidade da água na bacia do córrego Santo Antônio.

Considerando que a política de zoneamento, uso e ocupação do solo no município de Aparecida de Goiânia é relativamente recente sancionada em 2002, cerca de sete anos em vigor, conclui-se que está ainda não atingiu resultados satisfatórios quanto à melhoria da qualidade 
ambiental, proteção e preservação dos recursos hídricos no município.

O tratamento estatístico com a análise de correlação não paramétrica de Spearman auxiliou na identificação das correlações entre os parâmetros físico-químicos determinados nas águas da bacia do córrego Santo Antônio, confirmando os resultados quanto à influência da urbanização desordenada.

Os parâmetros analisados demonstram a variação da qualidade da água na bacia do córrego Santo Antônio entre os períodos chuvoso e seco indicando a influência direta do processo de uso e ocupação do solo apresentado nas zonas classificadas. Esta avaliação da qualidade da água gera a complexa reflexão sobre a ação antrópica no meio físico e nos recursos naturais.

Assim, recomenda-se o monitoramento dos parâmetros físico-químicos, a fim de manter os valores reais acertados aos estabelecidos pelo CONAMA com destaque para o córrego do Almeida e adequação dos lançamentos de efluentes da ETE Cruzeiro do Sul. A efetiva aplicação da política de uso e ocupação do solo; a elaboração de projetos de recuperação de áreas degradadas, como medidas compensatórias para as atividades que utilizam o solo na área da bacia; objetivando a melhoria da qualidade da água e ambiental da bacia do córrego Santo Antônio.

\section{Agradecimentos}

Os autores agradecem ao Laboratório de Geoquímica da Universidade de Brasília pela realização das análises e CAPES - Coordenação de Aperfeiçoamento de Pessoal de Nível Superior pela concessão de bolsa de pesquisa.

\section{BIBLIOGRAFIA}

1. Moreton, L.C.; Programa levantamentos geológicos básicos do Brasil: Goiânia Folha SE. 22-X-B-IV. Estado de Goiás. Escala 1:100.000. Org por Luís Carlos Moreton. Brasília, DNPM/CRPM, 1993.

2. Rodrigues, A.P. (coord.); Caracterização do Meio Físico, dos Recursos Minerais e Hídricos do Município de Aparecida de Goiânia. Superintendência de Geologia e Mineração ; Goiânia, 2005.
3. Associação Brasileira de Normas Técnicas; NBR 9898/1987: Preservação e técnicas de amostragem de efluentes líquidos e corpos receptores; 1987.

4. Andreoli, C.V.; Carneiro, C.; Gestão Integrada de Mananciais de Abastecimento Eutrofizados, Sanepar Finep ; Curitiba, 2005.

5. Carmo, M.S.; Boaventura, G. R.; Oliveira, E.C.; Quím. Nova. 2005, 28 (4).

6. Conselho Nacional do Meio Ambiente, Resolução; CONAMA 357/05: Estabelecer a classificação das águas, doces, salobras e salinas do Território Nacional, 2005.

7. IBGE. Relatório Conclusivo Referente aos Termos de Convênio n ${ }^{\circ}$ 004/95: Celebrado entre o Município de Aparecida de Goiânia e o IBGE. Aparecida de Goiânia, 1995.

8. Instituto de Pesquisa e Planejamento Urbano de Aparecida - IPPUA.; Relatório do Processo de Requalificação do Bairro Jardim Tiradentes: para o Fundo Nacional de Habitação e Interesse Social FNHIS. Aparecida de Goiânia, 2007.

9. Luchiari, A.; Identificação da Cobertura Vegetal em Áreas Urbanas: por Meio de Produtos de Sensoriamento Remoto e de um Sistema de Informação Geográfica. Revista do departamento de Geografia, USP : São Paulo, 2001.

10. Oliveira, C.J.F.; Dissertação de Mestrado, Universidade Federal de Goiás, Brasil, 2005.

11. Aparecida de Goiânia; Prefeitura de. Plano Diretor de Aparecida de Goiânia: Decenal 2001/2011, Aparecida de Goiânia, 2001.

12. Agência Goiana de Meio Ambiente - AGMA; Monitoramento Ambiental do Rio Meia Ponte. Disponível em: http://www3.agenciaambiental. go.gov. Acesso em: 06 Março, 2008. 


\section{Artigo 8}

\section{Sandro M. Pimenta ${ }^{*}$, Claudia V. de Lima', Tiago G. Ribeiro ${ }^{\text {1* }}$}

${ }^{1}$ IESA - Instituto de Estudos Socioambientais, Universidade Federal de Goiás - UFG.

*e-mail: moraisecologia@gmail.com

Telefone: +55(62) 81394513

**e-mail: godoiribeiro@gmail.com

Telefone: +55(62) 81466777 